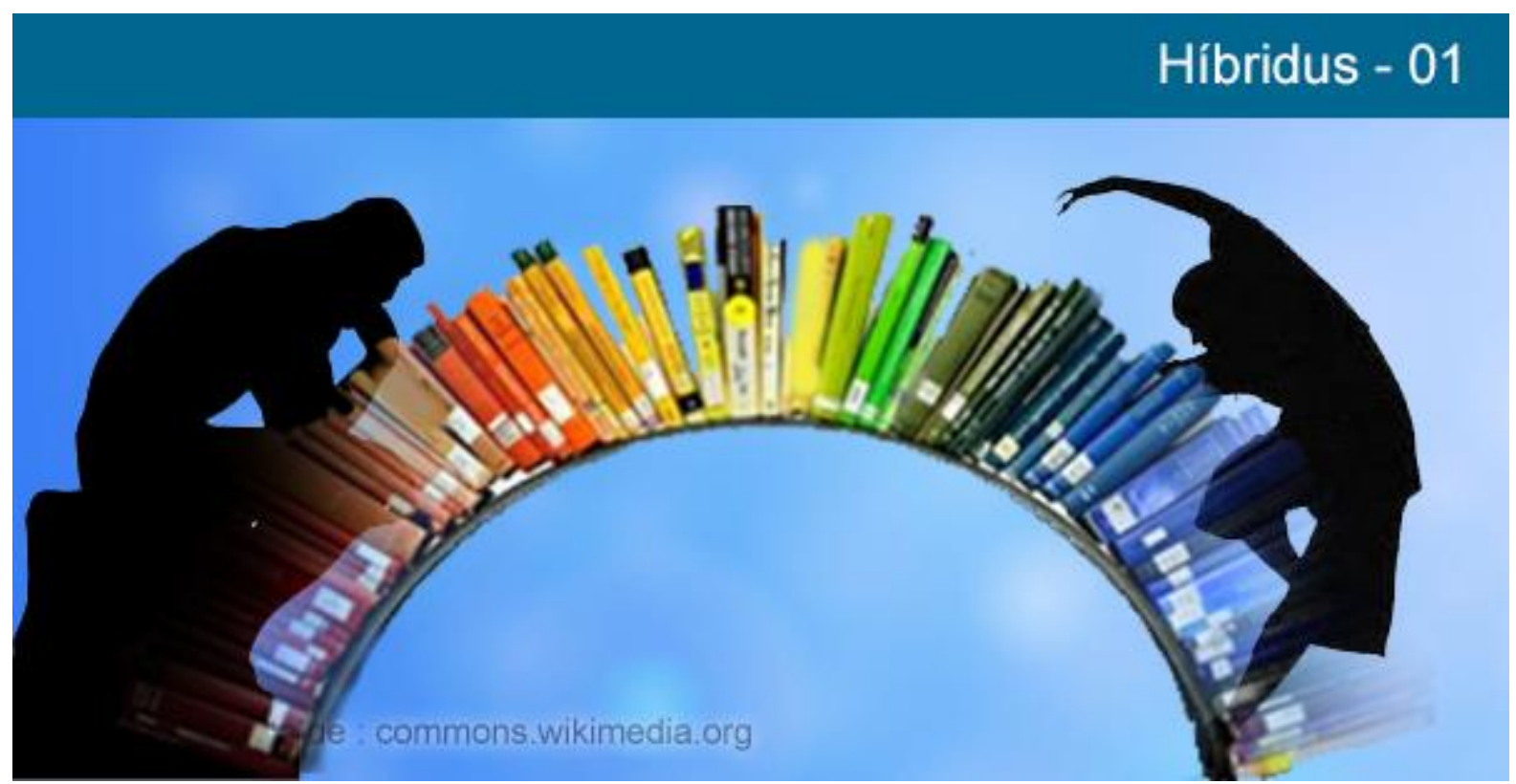

\title{
ARTE, CLÍNICA E TRANSDISCIPLINARIDADE
}

\section{Cristina Rauter}

Professora titular de Psicologia Social e Institucional do Departamento de Psicologia da Universidade Federal Fluminense; Pós-doutorado em Filosofia no Programa de Pós Graduação em Filosofia na UFRJ (2010) e na Universidade de Picardie Jules Verne D’Amiens, França (2011). Coordena o Núcleo Transdisciplinar Subjetividades, Violências e Criminalidade (TRANSCRIM).

\section{Catarina Resende}

Professora e coordenadora do curso de pós-graduação em Terapia através do Movimento - Corpo e Subjetivação da Faculdade Angel Vianna. Doutora em Psicologia - Estudos da Subjetividade/Clínica e Subjetividade, pela Universidade Federal Fluminense (2013). Bolsista CAPES/PDSE, em 2012, na Faculdade de Motricidade Humana da Universidade de Lisboa, Portugal.

Resumo: Este artigo explora áreas de interface entre arte e clínica no sentido de possibilitar uma ampliação no campo dos estudos da subjetividade. A partir de uma perspectiva transdisciplinar entre literatura, dança e filosofia, busca problematizar a prática clínica enquanto um exercício experimental que se dá na superfície e não na interioridade e que não pretende chegar a verdades universais. Seriam esforços da clínica, da poesia e da dança reativar a força vital das pequenas percepções no cerne da linguagem e dos corpos, religando as palavras ao mundo da experiência sensível, tornando o dizer uma forma dinâmica de vitalidade.

Palavras-chave: arte; psicologia clínica; transdisciplinaridade; poesia; dança.

\section{ART, CLINICAL PRACTICE AND TRANSDISCIPLINARITY}

Abstract: This article explores areas of interface between art and clinical practice in order to allow an enlargement in the field of the studies of subjectivity. Departing from a transdisciplinary perspective as an experimental exercise directed to surface and not to interiority, the goal is not to reach any universal truth. Some efforts in the field of clinical psychology, poetry and dance reactivate the vital force present in small perceptions in language and in the body, reconnecting words to the world of sensible experience, turning speech into a form of dynamic vitality.

Keywords: Art; Clinical Psychology; Transdisciplinarity; Poetry; Dance

\section{POLÊM!CA | Revista Eletronica da Uej}


Explorar as áreas de interface entre arte contemporânea e clínica pode trazer para este campo a possiblidade de ultrapassar certos impasses, permitindo a exploração de mundos pouco visitados em nossa subjetividade. Seguimos uma perspectiva transdisciplinar, que não diz respeito a anular as diferenças entre esses campos, mas colocá-los lado a lado, para que entrem em ressonância ou em relação de transversalidadade. A clínica, portanto, estará circunscrita numa zona de vizinhança com a arte, forçada nos seus limites por elementos de passagem, que Deleuze (2010) nomeou "intercessores", enquanto práticas e saberes limiares capazes de abri-la para o diálogo com outros campos, a partir de turbulências que marquem uma posição crítica ao mesmo tempo que coloquem a clínica em devir. Neste trabalho traremos algumas reflexões "entre" os campos da arte, em especial da literatura e da dança, e da filosofia, trabalhando com Nietzsche e Spinoza, preocupando-nos mais em saber "como isso funciona" do que "como isso se articula" (Rauter, 2012, p. 11). A intenção é fazer com que as intervenções do campo da psicologia clínica possam se beneficiar dessa "viagem experimental", desde já reconhecendo que trabalharemos com fragmentos e que permaneceremos num campo da dispersão, abrindo mão do ideal de chegar a verdades universais.

Apesar de sabermos, a partir da filosofia de Spinoza, que um indivíduo é composto de múltiplos indivíduos - ou que somos uma multidão, como dizem Deleuze e Guattari (1995, p.10) - o que verificamos é que nossas subjetividades quase sempre operam de forma simplificada ou reduzida, adquirindo com mais frequência modos de expressão falsamente unitários. Pensamos que as intervenções produzidas pelas várias formas de arte contemporânea sobre os processos de subjetivação podem possibilitar que os múltiplos indivíduos que nos compõem ganhem maior expressão. Efeitos de contágio podem agir no sentido inverso ao dos processos de simplificação e de imitação em ação no campo social.

Para Guattari (1992/2008), a arte contemporânea constrói um paradigma para uma clínica das subjetividades contemporâneas. Explorando essas relações de vizinhança entre a clínica e a arte, podemos trazer para a clínica esse caráter experimental por excelência da arte contemporânea. Para Deleuze e Guattari, "uma psicoterapia bem-sucedida poderia ter uma eficácia semelhante à do processo de criação artística, no sentido de produzir mutações no campo da subjetividade" (Deleuze, Guattari, 1976, p. 173). A arte contemporânea teria como uma função terapêutica, podendo nos trazer um outro tipo de saúde. Se pensarmos num

\section{POLÊM!CA | Revista Eletronica da veri}


inconsciente-produtor, pensado por Deleuze e Guattari em "O Anti-Édipo", com forte inspiração spinozista, a clínica se relacionaria imediatamente com a produção ou a criação de algo (Rauter, 2012, p. 122). Em Spinoza (2008), agir, viver e perseverar no ser são indissociáveis, ou como podemos ler em "O Anti-Édipo" de forma mais radical: se o inconsciente produz, ele produz real. Não seria o sonho a via régia para o inconsciente, como pensou Freud, mas antes a insônia, estado no qual não temos o nosso aparelho muscular em atividade reduzida como no sono e por isso podemos intervir diretamente na realidade com nossas produções oníricas, ou com nossa imaginação. Ao distinguir ilusão e fantasia, Winnicott (1975) reserva para o domínio da ilusão esse espaço onde a imaginação não pode ser desvinculada de seus efeitos, dos atos que é capaz de engendrar. O termo fantasia é reservado pelo autor para as manifestações da imaginação vinculadas à patologia, que expressam uma perda ou diminuição de toda essa potencialidade. O brincar infantil diz respeito ao reino da ilusão, mas brincar é fazer, é encontrar "os outros", é inventar um mundo, e desse modo, é algo que a um só tempo se apoia e produz coletivo. Há, em Winnicott, um vetor que vai do brincar infantil à cultura humana em sua dimensão criadora, ainda que saibamos que grande parte do que se denomina cultura hoje pode estar vinculado à produção de passividade, de obediência.

A arte contemporânea em suas diversas modalidades; a dança contemporânea, a performance art, o teatro contemporâneo, todos esses campos que se tornaram difíceis de distinguir uns dos outros, expressam essa indissociabilidade entre imaginar e agir que Winnicott tão bem soube perceber. Não se trata de representar o real em que vivemos, mas antes de produzir um outro real que seja capaz de problematizá-lo.

Nos termos winnicottianos (1954, p. 32), o dispositivo clínico tem uma ressonância com as mais diversas experiências culturais, a poesia, o lúdico, a amizade, que certamente podem funcionar no sentido terapêutico. No entanto, o vínculo terapêutico teria uma especificidade, pois seria aquele mais disposto a suportar a crueldade do exercício do viver; nomeadamente, o clínico se permite ser afetado pelo amor e pelo ódio do paciente, deve estar apto a suportar, acolher e manejar o jorro da vida na sua crueldade, agindo, tanto quanto possível, no sentido da transformação dessa experiência.

Winnicott aproxima o exercício clínico da afirmação trágica da vida. Essas expressões de "afetos tristes", para usar aqui uma linguagem spinozista, são, por certo, fruto de 
experimentações, de marcas que a partir delas se cristalizaram, e o clínico irá, tanto quanto possível, buscar outras linhas entre essas marcas, cicatrizar feridas, e desse modo, ter acesso a esse plano no qual a vida está em constante mudança. Se utilizamos a expressão "tanto quanto possível" é porque não acreditamos que o terapeuta seja sempre bem sucedido nesta empreitada e que efetivamente possa acolher toda a crueldade do paciente, pois que poderá ser afetado por forças superiores às suas. Além disso, há um outro ensinamento nietzschiano com relação ao tempo que tudo transforma: o de que nada volta a ser o que já foi e neste sentido, as marcas não podem ser apagadas.

Em Nietzsche há uma ligação visceral da arte com a vida, com a poesia e com a dança em especial, e também com a vida que há na loucura, como podemos ver no Zaratustra. A “superação do homem”, para este filósofo, só será possível se este percorrer esse caminho. Se pensarmos que no campo da clínica estamos buscando transformações subjetivas no sentido da potencialização da vida, ou da vida que há na loucura, daí podemos compreender o sentido dessa relação de transversalidade com a arte que pretendemos explorar. Numa relação de vizinhança com a arte contemporânea, a clínica talvez possa tornar-se mais capaz de incluir outras formas de expressão para além da verbal, estabelecendo relações de porosidade com o plano das intensidades, das sensações. Porém dizer que a arte opera no plano das sensações é diferente de dizer que se relaciona com o sentimento psicológico, pois ela nos leva, não a uma exploração de interioridades, mas justamente a sair de nós mesmos.

O esquecimento, tal como pensado por Nietzsche, nos traz reflexões que podem ser úteis para a clínica, levando-a a um afastamento radical da investigação do passado e das profundidades psicológicas (Rauter, 2012, p. 107-109). A clínica se volta para uma superfície de experimentação, deslocando-se do desvelamento do passado ou do que está "por trás" para a atenção aos novos agenciamentos que se produzem e se atualizam nas relações com os objetos do mundo e também na relação terapeuta-cliente. Essa relação, no entanto, é apenas um recorte da dimensão do coletivo na qual se insere. A superfície de experimentação aberta ao deixarmos o plano das interioridades psicológicas é uma superfície onde múltiplos encontros se dão. Porém não se trata de "relações humanas", mas de encontros com multiplicidades e intensidades que se dão num território. Essa clínica pensada numa superfície de experimentação é, pois, uma clínica política, assim como a arte contemporânea, que com suas experimentações, opera diretamente sobre uma política do cotidiano.

\section{POLÊM!CA | Revista Eletronica da veri}


Trazendo a noção nietzschiana de esquecimento para nossa reflexão, talvez possamos pensar que na clínica se trata não de buscar no passado qualquer verdade sobre nós mesmos, mas, fundamentalmente, de produzir um inconsciente-superfície e de catalisar deslocamentos intensivos. Desse modo, o analista se tornaria um "viajante-construtor de novos mundos" e de novos processos de subjetivação, com toda a prudência a que essa empreitada também nos obriga.

Otto Rank, o guarda-livros do grupo das quartas feiras que se reunia na casa de Freud, naqueles tempos pioneiros da psicanálise, era leitor de Nietzsche e colocou a questão de que a psicanálise foi capaz de pensar a neurose, mas não foi tão bem sucedida em pensar a vida do artista ou do militante revolucionário. Isto porque o tipo de saúde que a criação artística ou a militância podem trazer não está referida a um equilíbrio entre desejos e obrigações, entre realidade e prazer. Essa saúde deve ser compreendida na radicalidade dos processos criativos em seus "devires revolucionários" (Deleuze, 1988), pondo em ação "forças cósmicas”, como já referia Rank (1978) no final dos anos 30 do século passado.

A obra de Proust propõe uma prática experimental de rompimento com toda a transcendência, chamando o leitor a experimentar com sua própria vida. Através da literatura, ele nos ensina a fazer o eu involuir de suas máscaras ou capas, desfazendo-se delas e podendo reencontrar uma vida verdadeira através dos signos da arte (Rauter, 2012, p. 145).

Um ensinamento que o contato com a literatura pode trazer para a clínica é a possibilidade "suportar o caos", no mesmo sentido explorado por Winnicott em "O Brincar e a Realidade" quando se refere ao analista que tem sempre uma interpretação na ponta da língua quando não consegue suportar o caos. Na vida ordinária podemos apenas experimentar o caos como negatividade, como perturbação. No entanto, para Proust o tropeço é fundamental (Deleuze, 1987, p. 57): é ele que, a partir do corpo, nos desestabiliza, e pode nos conduzir a outra sensibilidade que permanece encoberta e que precisa continuamente ser reencontrada. Ou a experimentação com a madeleine; o bolinho que embora trivial e cotidiano, pode estabelecer repentinamente contato com temporalidades intensivas das quais já nos afastamos.

A literatura e a poesia podem nos trazer mais próximos de uma escuta polifônica capaz de melhor trabalhar com sentidos múltiplos e com as instabilidades e intensidades inerentes aos processos de subjetivação contemporâneos. Qual a especificidade da dança, que 
possibilidades ela abre no sentido em que estamos construindo? A dança tem a potência de nos ensinar a melhor incluir no processo terapêutico os agenciamentos que o cliente faz com seu corpo, com o ambiente, com o coletivo e com a vida atual. De acordo com José Gil (2005), o campo da dança opera por uma abertura dos corpos às pequenas percepções, a uma zona de contágio com os outros corpos e com as intensidades do mundo. Na abertura dos corpos às pequenas percepções, a superfície de experimentação da clínica se dilata na capacidade de ampliar os acontecimentos, inverter as escalas das micro e macropercepções a ponto de criar uma nova percepção do mundo, numa dimensão afetiva intensiva dos encontros nessa zona de contágio. Trata-se de uma experiência paradoxal, que se abre às zonas de turbulência ou aos fenômenos de limiar. Ao trazer a dança como mais uma interface entre arte e clínica, ressaltamos o corpo como ponto de partida para nos desestabilizar e nos abrir a novas sensibilidades, tal como em Proust. Assim, o corpo é compreendido antes como uma corporeidade, como um território existencial constituindo-se, ininterruptamente, por multiplicidades e intensidades, de modo sempre singular e num incessante criar e recriar-se.

Podemos dizer, de sobressalto, que a poesia é uma dança da linguagem, liberando os devires da significância. Lançada na experiência da clínica, pode vir a ser uma política de dizibilidade dos estados intensivos, da multiplicidade dos processos de subjetivação (Resende, 2013). Se passamos bruscamente da dança à poesia, é porque acreditamos que essa experiência sensível na charneira dança-poesia poderia inspirar o analista a emprestar seu corpo para que o cliente faça novos agenciamentos, levando-o a uma concepção de transferência que radicaliza a materialidade corporal dos afetos em jogo entre terapeuta e cliente. $O$ terapeuta sabe que se move na transferência, numa dança intensiva do encontro que sustenta uma concepção de transferência próxima das sintonias afetivas descritas por Daniel Stern (1985) entre mãe e bebê, nas quais são captados afetos de vitalidade.

Nesta perspectiva, a sintonia afetiva seria um entroncamento entre sensibilidade $e$ expressividade, onde se comunicam as impressões qualitativas do relacionamento por meio das intensidades, da duração e das formas dinâmicas de vitalidade (Stern, 1992, 2010¹). Na clínica, os afetos de vitalidade configuram-se na escala microscópica das pequenas percepções, por estados afetivos indefiníveis, por uma apreensão sensória imediata, por uma

\footnotetext{
${ }^{1}$ Assim, no seu último livro publicado, Stern propõe uma torção no termo para "formas dinâmicas de vitalidade", enfatizando ainda mais o estado inapreensível e não categórico desse estado sensível (Stern, 2010). Aqui optamos por manter as duas maneiras de designá-los.
} 
vibração tátil, pelos quais expressamos as variações intensivas e tonais. O outro está fora e dentro, porque existe uma sintonia dos afetos de vitalidade que sofre variações, diferenciações.

Stern (2010) faz uma aliança com as "artes baseadas no tempo", ou artes de linguagem não-verbal, nomeadamente, a dança, a música, e certos tipos de teatro e cinema. Segundo ele, as artes baseadas no tempo apresentam-se em tempo real, sem seguirem a lógica da representação como fio condutor hegemônico para a expressividade. Essas artes seriam um meio privilegiado de experimentar de forma crua as dinâmicas de vitalidade, visto que o seu exercício estético é performatizar essas intensidades do estado sensível num grau ampliado, refinado, exercitado repetidamente.

O interesse especial pelo campo das artes nesta abordagem transdisciplinar se justifica na medida em que encontra nelas um dispositivo catalisador da experiência sensível. Não só porque dão às formas de sensações uma apurada capacidade expressiva de compartilhamento, mas por elas serem o campo pioneiro na exploração da dimensão dinâmica da experiência humana. Mais do que qualquer ciência ou psicologia, a arte é a área que se ocupou, por mais tempo, de um modo de elaborar as formas dinâmicas de vitalidade. É próprio da arte criar caminhos para encontrar, identificar, lapidar, expressar formas dinâmicas de vitalidade, que possam ser compartilhadas no plano comum.

Stern indica que a capacidade da linguagem de ir além da experiência vivida imediata seria a sua maior virtude, para o "bem" e para o "mal". Ou seja, ela incide perpendicularmente sobre os processos de subjetivação, criando novos sentidos, novas imagens, mas também distorcendo, generalizando e cristalizando outros. Nessa perspectiva, a linguagem é tomada como "reino do devir" e não como "reino da verdade", sublinhando-se aqui a linguagem como estando em transformação constante e não admitindo submissão a nenhum modelo ou lógica (Rauter, 2012, p. 56). Seriam esforços da clínica e da poesia reativar a força vital das pequenas percepções no cerne da linguagem, religando as palavras ao mundo da experiência sensível, fazendo do dizer mais uma forma dinâmica de vitalidade. Se há uma verdade nas palavras, esta diz respeito não a alguma lógica que elas conteriam, mas ao plano de intensidades que a atravessa.

Na construção de uma superfície de experimentação que é como uma dança dos afetos de vitalidade, compreendemos a transferência como um campo dinâmico de agenciamentos 
corporais intensivos. Acreditamos que construir um plano de superfície na abordagem transdisciplinar da clínica é criar um dispositivo de circulação permanente de forças que recolocam de maneira radical o analista nesta cena. No encontro intensivo com o cliente, o terapeuta deve estar disponível com seus próprios afetos para ultrapassar a si mesmo diante da recriação de mundos (Resende, 2013, p. 145-150).

Nietzsche toma a poesia e a dança como caminhos para a superação do ressentimento, contra a passagem do tempo que tudo transforma. A possibilidade de afirmação máxima da vontade, a superação do homem e de todo o ressentimento, só podem se dar se houver um deslocamento subjetivo que tem na arte um caminho privilegiado. O passado não pode ser destruído nem alterado nele mesmo, mas há uma transformação existencial possível que pode tornar o passado motor da criação. Essa transformação, operada pelo poeta e pela loucura, é uma aproximação criadora daquilo que foi, para construir o que será.

\footnotetext{
E como suportaria eu ser homem, se o homem não fosse também, poeta e decifrador de enigmas e redentor do acaso! Redimir os passados e transformar todo "foi assim" num "assim eu o quis!"- somente a isto eu chamaria redenção![...] E eis que uma nuvem após outra entrou a rolar sobre o espírito; até que a loucura, por fim, pregou: tudo perece, tudo, portanto, merece perecer! (Nietzsche, 1977, p.151).
}

Convidemos neste momento o poeta Fernando Pessoa para entrar nesse diálogo. Contemporâneo de Proust, Pessoa propõe uma rachadura na realidade instituída a partir de um desmoronamento na fantasia de que o eu poderia ser uma única identidade instituída. Atravessando uma experiência limite da multiplicidade, nos mostra que "a arte tem valia porque nos tira daqui”, tornando-nos mais capazes de ultrapassarmos a nós mesmos a partir de uma prática experimental imanente. A arte pode nos aproximar da possibilidade de transformar a própria vida em laboratório poético e a si mesmo em analisador das sensações. Na doutrina estética do Sensacionismo (Pessoa, 1966, 1980, 2006), o próprio poeta oferece-se como matéria sensível a ser esculpida. O Sensacionismo, movimento literário criado por Fernando Pessoa e Mário de Sá-Carneiro, propõe que a única realidade é aquela capaz de ser apreendida pelas pequenas percepções, pelas formas dinâmicas de vitalidade: "Sentir é criar. /Sentir é pensar sem ideias, e por isso sentir é compreender, visto que o Universo não tem ideias. " (Pessoa, 1966, p. 216).

Pessoa faz de sua própria "alma, uma ética e uma estética", se torna um poeta “analisador de sensações", que se instala nos interstícios do sono e da vigília, da passividade e

\section{POLÊM!CA | Revista Elêrônica da Uej}


da atividade, descolando-se da percepção macroscópica da história dos fatos reais, para provocar o maior número de "acontecimentos de sensações", num dentro-fora de si. Pessoa aprende a sentir com as palavras, constrói uma superfície das intensidades que abre o fundo comum das palavras, das imagens e das sensações.

No Livro do Desassossego, Fernando Pessoa (2008) escreve pelas mãos de seu semiheterônimo Bernardo Soares aquilo que define como uma biografia sem fatos, tal como os personagens sem história de Proust. Sem uma história para contar, o ajudante de guarda-livros Bernardo Soares nos leva ao longo de mais de 500 páginas compostas por fragmentos de si mesmo que vão montando uma superfície construída a partir dos seus agenciamentos com a paisagem, o céu de Lisboa, o rio Tejo, os transeuntes, a leiteira, as ruas da Baixa... É uma "biografia" sem origem nem ponto de chegada, mas uma biografia-ponte sobre a experiência de ultrapassar a si mesmo, de tocar o plano do devir.

Com uma biografia dilatada numa espécie de presentidade, sem um passado infantil que revele qualquer verdade sobre si mesmo, Bernardo Soares discorria sobre o valor da infância, não mais da vida de um sujeito, mas da linguagem para a plenitude da produção poética. Ao transformar gestos e sensações em palavras, Soares cria verbalizações lúdicas em um plano de expressão poética, na imanência do sentir e do dizer, para uma saúde da existência. Acredita que saber exprimir-se com a simplicidade da criança é renovar o verbo por meio da expressão estética das singularidades, desobstruir os grilhões da linguagem, tomando-a como ferramenta para pulverizar o utilitarismo de uma única realidade.

"Renovar o verbo" é criar um jogo lúdico de dançar com as palavras. Na perspectiva winnicottiana, para uma análise ser bem sucedida, terapeuta e cliente precisam ser capazes de brincar, ambos passam a habitar um espaço limiar entre o interior e o exterior, no "lado onírico da vigília”. Essa terceira área intervalar, inerente à prática do cuidado e da criação artística, permite o jogo entre a realidade interna e externa, o corpo intensivo e o corpo empírico, de forma indistinta, em que algo novo pode surgir. No espaço limiar, o brincar e a experiência cultural vinculam passado, presente e futuro ocupando tempo e espaço, engendrando devires.

$\mathrm{Na}$ interface entre dança e poesia, na tessitura de uma experiência clínica invadida e nutrida pelos fenômenos curativos da vida cotidiana e da arte, o terapeuta analisador das sensações é atravessado pelas forças cruas do amor e do ódio, tendo como desafio empenhar-

\section{POLÊM!CA | Revista Eletronica da Ueij}


se num rigoroso exercício de si, a fim de construir em seu corpo a casa dos novos possíveis. Na experiência da clínica, co-habitamos um campo de ressonâncias, contrações, sustos, choques, fricções, atritos, por onde irrompem os desvios, as diferenciações, os devires. Pela maternagem, a arte sutil de reassegurar o direito de existir, leva o analista a oferecer seu próprio corpo como mapa, para que o paciente possa construir um domínio de si (Resende, 2013, p. 147).

"Substitui-te sempre a ti próprio. Tu não és bastante para ti. Sê sempre imprevenido por ti próprio. Acontece-te perante ti próprio. Que as tuas sensações sejam meros acasos, aventuras que te acontecem", indica Pessoa (1966, p. 216) ao falar sobre o Sensacionismo. Para a capacidade de devir-Tejo, devir-leiteira, devir-outro, enfim, Pessoa precisou criar um verbo: outrar-se. Assim, o Livro do Desassossego é uma biografia de outramentos, de sucessivos devires-outro. Ele vai seguir na construção de um plano de imanência do sentir e do dizer em busca de uma saúde da existência, porque, segundo ele, saber exprimir-se é renovar-se. Retornamos aqui a essa compreensão da linguagem a que já nos referimos, na qual esta seria o reino do devir, onde tudo está em constante mudança, e não um livro aberto a ser decifrado segundo parâmetros fixos.

Para Pessoa, a literatura é o esforço para tornar a vida real, e o único meio de transmitir toda a complexidade das suas impressões, buscando se libertar de uma única realidade utilitária. Pessoa persegue pelo ato de escrever, uma forma de se garantir lúcido na experiência do limite de si, ao fazê-lo pela via dos "bailados verbais". Pessoa dança com as palavras, e nos toca com a voz que a conduz. Eis uma das razões para trazer Pessoa para o diálogo com a abordagem transdisciplinar da clínica: a construção de um plano comum entre a dança e a poesia, fazendo do dispositivo clínico um laboratório poético, e do terapeuta um analisador das sensações, na mesma direção seguida por Stern, já referida neste artigo.

Ao tomar a transferência enquanto dispositivo capaz de produzir agenciamentos, o analista se conecta com as sensações do cliente como ponto de partida para novas modulações nas subjetividades. Há um dançar compartilhado que permite brincar com palavras atravessadas por intensidades e produz outramentos em ambos: no terapeuta e no cliente. Ao construir uma política do cotidiano na clínica, com a criação de uma superfície engendrada pelos "acontecimentos de sensações", isto é, pela emergência das sensações e as interferências subjetivantes que daí ocorrem, o terapeuta faz dos limites de sua alma uma ética e uma 
estética: "Sentir é compreender. Pensar é errar. Compreender o que outra pessoa pensa é discordar dela. Compreender o que outra pessoa sente é ser ela. Ser outra pessoa é de uma grande utilidade metafísica. Deus é toda a gente” (Pessoa, 1966, p. 216).

Em um trecho do Livro do Desassossego, Bernardo Soares descreve os sentidos dessa direção ética assumida por Fernando Pessoa: ao negar uma dimensão progressiva (evolutiva) da vida subjetiva, muda de personalidades deslocando-se por "planícies", ou seja, viaja por uma mobilidade intensiva que o faz deslizar na superfície de uma involução criadora. Nesse plano de intensidades, os sentidos afetam uns aos outros, se comunicam por contágio, embora mantenham sua singularidade, ao modo do "tuning" descrito também por Daniel Stern (1985). Nesta perspectiva, o bebê opera sua relação com o mundo por uma "percepção amodal” que é a capacidade sinestésica de reconhecer visualmente algo que apenas experimentou pelo tato, por exemplo, numa espécie de "leitura" de um sentido pelo outro. Não há um privilégio da linguagem na decodificação desses universos sensíveis. É possível reformular uma vida inteira apenas por contemplar um fragmento de muro amarelo na pintura de Vermeer, como refere Proust (1993, p. 105), ou dançar apenas por ver dançar:

\begin{abstract}
A vida é uma viagem experimental, feita involuntariamente. É uma viagem do espírito através da matéria, e como é o espírito que viaja, é nele que se vive. Há, por isso, almas contemplativas que têm vivido mais intensa, mais extensa, mais tumultuariamente do que outras que têm vivido externas. O resultado é tudo. O que se sentiu foi o que se viveu. Recolhe-se tão cansado de um sonho como de um trabalho visível. Nunca se viveu tanto como quando se pensou muito.

Quem está ao canto da sala dança com todos os dançarinos. Vê tudo, e, porque vê tudo, vive tudo. Como tudo, em súmula e ultimidade, é uma sensação nossa, tanto vale o contacto com um corpo como a visão dele, ou, até, a sua simples recordação. Danço, pois, quando vejo dançar. (Pessoa, 2008, p.345-346)
\end{abstract}

\title{
Referências biliográficas:
}

DELEUZE, D. Proust e Os Signos. Rio de Janeiro: Forense Universitária, 1987.

G de Gauche. O Abecedário Gilles Deleuze. Transcrição integral para fins didáticos. Realização de Pierre-André Boutang, TV Brasil, Tradução e Legendas Raccord. 1988.

Conversações (1972-1990). São Paulo: Ed. 34, 2010. $2^{\mathrm{a}}$ Ed.

DELEUZE, G.; GUATTARI, F. O Anti-Édipo. Rio de Janeiro: Imago, 1976.

Mil Platôs: capitalismo e esquizofrenia. Vol. 1. Rio de Janeiro: Ed. 34, 1995.

\section{POLÊM!CA | Revista Eletronica da Uej}


GIL, J. Movimento Total: o corpo e a dança. São Paulo: Iluminuras, 2004.

GUATTARI, F. Caosmose: um novo paradigma estético. São Paulo: Ed. 34, 1992. 5 $5^{\text {a }}$ reimpressão - 2008.

NIETZSCHE, F. Assim Falou Zaratustra. Rio de Janeiro: Civilização Brasileira, 1977.

PESSOA, F. Páginas íntimas de auto-interpretação. Lisboa: Ática, 1966.

Lisboa: Ática, 1980.

Apontamentos para uma estética não-aristotélica (1924-1925). Textos de crítica e intervenção.

Textos filosóficos. Lisboa: Nova Ática, 2006. vol. I.

Livro do desassossego: composto por Bernardo Soares, ajudante de guarda-livros na cidade de Lisboa. Org.: Richard Zenith. São Paulo: Companhia das Letras (Companhia de Bolso), 2008.

PROUST, M. Em Busca do Tempo Perdido. Vol. VII. Rio de Janeiro: Ediouro, 1993.

RANK, O. Art and artist: creative urge and personality development. London: W.W. Norton \& Company, 1978.

RAUTER, C. Clínica do Esquecimento. Niterói: EdUFF, 2012.

RESENDE, C. Escutar com o corpo: a experiência sensível entre dança, poesia e clínica. Tese (Doutorado) Universidade Federal Fluminense, Instituto de Ciências Humanas e Filosofia, Departamento de Psicologia, 2013.

SPINOZA, B. Ética. Belo Horizonte: Autêntica Ed., 2008. $2^{\text {a }}$ Edição bilingue latim/português.

STERN, D. The interpersonal world of the infant. New York: Basic Books, 1985.

Forms of vitality: exploring dynamic experience in psychology and the arts. New York: Oxford University Press, 2010.

WINNICOTT, D. W. Aspectos clínicos e metapsicológicos da regressão no contexto psicanalítico (1954). Da pediatria à psicanálise: obras escolhidas. Rio de Janeiro: Imago, 2000.

O brincar e a realidade. Rio de Janeiro: Imago, 1975. 